\section{Família e demografia em Minas Gerais, séculos XVIII, XIX e XX}

\author{
Douglas Cole Libby* \\ Tarcísio R. Botelho** \\ Cristiana Viegas de Andrade***
}

O presente texto visa divulgar os trabalhos do projeto de pesquisa "Família e demografia em Minas Gerais, séculos XVIII, XIX e XX", financiado pela Fapemig e pelo CNPq, por meio do Programa de Apoio a Núcleos de Excelência - Pronex, e coordenado pelo prof. Douglas Cole Libby. Suas atividades se estenderão de novembro de 2009 a novembro de 2013, envolvendo 16 pesquisadores principais pertencentes a sete universidades de Minas Gerais, além de 29 pesquisadores associados de outras instituições do país e do exterior. O projeto é ligado ao Grupo de Pesquisa "População e Economia de Minas Gerais", do CNPq, liderado pelos professores Douglas Cole Libby e Tarcísio Botelho e vinculado à Universidade Federal de Minas Gerais (UFMG).

Os objetivos foram definidos em consonância com o projeto "Além do CentroSul: por uma história da população colonial nos extremos dos domínios portugueses na América", coordenado pelo prof. Sérgio Odilon Nadalin, da Universidade Federal do Paraná, e conectado ao Grupo de Pesquisa "Demografia \& História". Ambos os projetos mantêm um grau de articulação, uma vez que procuram discutir questões semelhantes para espaços diferentes no Brasil: Minas Gerais, para o nosso caso; e Pará, o Nordeste brasileiro e o extremo-sul, para o projeto "Além do Centro-Sul".

$\mathrm{O}$ texto divide-se em quatro partes. Primeiramente, são explicitados os objetivos e metas do projeto, inserindo-os na discussão teórico-conceitual que os orienta. Em seguida, apresentam-se as fontes documentais que estão sendo levantadas. A terceira parte mostra o andamento da pesquisa, com a descrição dos bancos de dados que foram construídos até o momento. Os resultados esperados com a conclusão do projeto são expostos nas considerações finais.

\section{Objetivos e metas do projeto}

O objetivo geral do projeto é investigar a história da família em Minas Gerais desde o século XVIII até meados do século XX, tomando como dimensão central da análise a relação dinâmica entre mobilidade e estabilidade que marca o povoamento e a ocupação do espaço mineiro. Para tanto, leva-se em consideração a diversidade dos regimes demográficos brasileiros, entendendo-se regime demográfico como o conjunto de relações que estão na base da reprodução biológica e da reprodução social de uma dada população. Partindo de algumas sistematizações pioneiras (MARCÍLIO, 1984; NADALIN, 2003), propõese, como hipótese de trabalho, que esse esforço analítico se oriente a partir da consideração da diversidade de regimes demográficos que teriam vigorado, parcial ou plenamente, em Minas Gerais.

Como o foco da pesquisa é Minas Gerais, compreende-se porque o século XVIII é seu ponto de partida. A complexa

\footnotetext{
* Doutor em História Social pela USP, professor do Departamento de História da Universidade Federal de Minas Gerais (UFMG), bolsista de Produtividade em Pesquisa do CNPq.

** Doutor em História Social pela USP, professor do Departamento de História da Universidade Federal de Minas Gerais (UFMG), bolsista de Produtividade em Pesquisa do CNPq.

*** Doutora em História pela University of Cambridge, bolsista de Pós-Doutorado Júnior da Fundação de Amparo à Pesquisa do Estado de Minas Gerais (Fapemig).
} 
aventura mineradora, com suas implicações no abastecimento e consolidação do mercado interno, passou por múltiplas transformações até o desembarque da corte portuguesa em 1808. Apesar de sua ampla diversidade regional, as Minas Gerais seguiram o século XIX adentro constituindo um dos principais alicerces do Oitocentos brasileiro e, com efeito, possuindo o maior plantel provincial de escravos até o momento da emancipação geral, em 1888. ${ }^{1} \mathrm{Na}$ Primeira República, Minas Gerais continuou se destacando como o Estado brasileiro com a maior população e o segundo maior produtor de café.

Tendo estas questões como pano de fundo, a pesquisa busca reconsiderar e reavaliar interpretações sobre a dinâmica demográfica do passado, caracterizada por altas taxas de natalidade e de mortalidade (típicas do período pré-transição demográfica), bem como identificar, em cada contexto (geográfico, econômico, social e cultural), os momentos de alteração/declínio destas taxas que caracterizariam o início do processo de transição demográfica que vai resultar nos regimes demográficos modernos. Isto ocorreu em um quadro de mobilidade versus sedimentação que marca a ocupação de todo o interior brasileiro e também de Minas Gerais.

Identificar, mensurar e espacializar em Minas Gerais, do século XVIII ao XX, os elementos desta complexa dinâmica demográfica é o desafio a que a pesquisa se propõe. O profundo conhecimento das fontes e a montagem de um consistente banco de dados serão elementos-chave para o conhecimento da geografia e da história dos regimes demográficos mineiros no período estudado.

\section{As fontes documentais}

Para alcançar os objetivos propostos, a estratégia de pesquisa concentra-se no levantamento dos registros paroquiais de batismos, casamentos e óbitos de diversas paróquias mineiras, escolhidas com o propósito de serem representativas da diversidade de regimes demográficos assumida como hipótese de trabalho. Também estão sendo agregados os levantamentos de caráter censitário e nominativo disponíveis para diversas localidades mineiras e inventários post mortem recolhidos pelos pesquisadores envolvidos no projeto.

Os registros paroquiais existem desde o início da colonização portuguesa na América, mas apenas a partir de meados do século XVIII encontram-se séries mais abundantes e completas. Além disso, apenas após a Proclamação da República no Brasil houve a implantação do registro civil, que permaneceu pouco efetivo até períodos bastante recentes.

Embora os registros paroquiais tenham uma série de limitações (falta de normas de transmissão de sobrenomes, variações do nome ao longo da vida de uma pessoa, omissões de inúmeras informações por parte de alguns párocos, altos índices de sub-registro), a favor do seu uso pesam inúmeros fatores. Em primeiro lugar, é a fonte documental mais disseminada por todo o território nacional (e consequentemente mineiro), já que a paróquia foi, durante o período colonial e imperial, a unidade administrativa que mais penetrou no território brasileiro. Em segundo, trata-se da fonte mais uniforme em termos da sua apresentação e sistematicidade. Em terceiro lugar, constitui um tipo de fonte utilizada em uma ampla bibliografia, nacional e internacional, o que permite a comparação dos dados dela extraídos. Finalmente, é seguramente o tipo documental de caráter local que mais sobreviveu ao longo do tempo, podendo ainda ser encontrado em grandes quantidades por vastas regiões mineiras.

O levantamento de fontes primárias realizado pelo Centro de Estudos Mineiros

\footnotetext{
${ }^{1}$ Sobre Minas Gerais no século XIX, há um extenso debate; ver Martins (1980, 1983), Slenes (1985), Libby (1988), Paiva (1996), Rodarte (2008).
} 
constatou que os registros paroquiais são o tipo documental mais volumoso e disseminado em Minas Gerais. ${ }^{2}$ Como contraface, Minas Gerais seguramente detém o maior volume desse tipo de documentação no Brasil, em termos tanto da quantidade de paróquias que preservaram seus acervos quanto do período temporal abrangido, muitos deles remontando às primeiras décadas do século XVIII. Ademais, a Sociedade Genealógica de Utah realizou um volume enorme de microfilmagens de arquivos diocesanos e paroquiais em Minas Gerais e recentemente disponibilizou esse acervo para consulta pela Internet. ${ }^{3}$

A amostra inicial de paróquias a serem abordadas na pesquisa foi composta por aquelas que já haviam sido alvo de levantamentos (parciais ou totais) ou que estavam em vias de serem trabalhadas por historiadores. Tais paróquias apresentam: uma distribuição por quase todo o território mineiro; uma diversidade de situações geográficas e econômicas, que contemplam os critérios definidores dos regimes demográficos; o fato de muitas delas sediarem vilas/cidades; a disponibilidade de séries longas de registros paroquiais; e a existência de outros conjuntos de fontes entre as selecionadas pela pesquisa. As localidades escolhidas para integrarem a amostra de paróquias mineiras são: Aiuruoca, Baependi, Barbacena, Belo Horizonte, Bocaiúva (Bonfim), Campanha, Catas Altas do Mato Dentro, Coração de Jesus, Diamantina (Tejuco), Grão-Mogol, Itacambira, Januária, Mariana, Montes Claros, Ouro Preto (Paróquia de N. S. do Pilar), Paracatu, Piranga, Rio Pomba, Sabará, Santa Luzia, São João Del Rei, São Sebastião, Serro e Tiradentes (São José do Rio das Mortes).

Pretende-se, de modo complementar, recorrer aos inúmeros levantamentos censitários realizados ao longo do período, a fim de se traçar o pano de fundo e estabelecer o significado estatístico dos dados apurados a partir das fontes documentais principais. Para Minas Gerais provincial, existem duas séries importantes de listas nominativas de habitantes, uma para 1831-32 e outra para 1838-40. ${ }^{4}$ Além destas listas nominativas, há um conjunto de mapas de população, baseados nos distritos de paz e datados de 1833-1835. Também já foram coletadas listas nominativas de habitantes para 1804 e róis de confessados para o final do século XVIII e início do XIX.

No final do século XIX, houve a realização do Recenseamento Geral do Império (em 1872), primeiro censo geral brasileiro e único do período escravista (BOTELHO, 1998; SENRA, 2006). Os censos seguintes foram realizados após o fim da escravidão, mas serão úteis para o estudo dos regimes demográficos posteriores a 1850. Destacase, sobretudo, o censo de 1920 que, além de sua boa qualidade, foi acompanhado do primeiro censo econômico brasileiro. $\mathrm{O}$ censo de 1872 encontra-se digitado e já se iniciou a digitação do de 1920.

O outro conjunto documental importante para os propósitos do projeto refere-se aos inventários post mortem. O uso de documentação cartorial para estudos demográficos, embora apresente sérios problemas, torna-se relevante dada a escassez de fontes, típica do período pré-censitário. Por outro lado, algumas dimensões importantes dos sistemas familiares em suas conexões com os regimes demográficos só podem ser percebidas, no Brasil, por meio dessas fontes. É o caso da composição da riqueza familiar e dos padrões de transmissão de bens entre as gerações.

Conforme foi destacado anteriormente, estamos fazendo o levantamento ou a

\footnotetext{
2 Consultar Guia dos arquivos e acervos documentais históricos de Minas Gerais, 1522-1945 (www.fafich.ufmg.br/cem). Ver também Libby, Hargreaves e Martins (1999).

3 O site que disponibiliza as imagens denomina-se Family Search (https://www.familysearch.org/).

4 Estes conjuntos documentais estão sendo trabalhados por pesquisadores do Cedeplar/Face/UFMG, codificando e digitando as informações neles contidos. Alguns resultados preliminares obtidos encontram-se em Paiva (1996), Andrade (2001) e Rodarte (2008), entre outros.
} 
padronização dos registros de batismos, casamentos e óbitos nas diversas localidades selecionadas, procurando iniciar pelas datas mais recuadas no tempo. O início das séries documentais varia de acordo com a data de criação das paróquias e as condições de conservação desses documentos ao longo dos séculos. Como data final, indica-se o ano de 1888 (fim da escravidão), podendo-se estender até 1940. Como um grande número de paróquias selecionadas no momento inicial da pesquisa já tinha seus dados de registros paroquiais parcial ou totalmente levantados, boa parte do trabalho foi voltada para a padronização dos bancos de dados. Foram preservadas as informações nominais, para que se possa fazer o cruzamento nominal das informações, utilizando os próprios registros paroquiais ou outras fontes de dados que tragam informações também nominais.

Para a documentação de caráter censitário, nomeadamente as listas nominativas de habitantes, temos utilizado bancos de dados já existentes (com raras exceções), investindo-se na sua correção e padronização. ${ }^{5} \mathrm{Em}$ tais bancos de dados, as informações foram coletadas em sua integridade, sempre procurando preservar a informação nominal. Para todos os outros dados, foram atribuídos códigos numéricos às variáveis, o que permite seu uso direto por softwares de análise estatística.

Para a documentação cartorária (inventários post mortem), também estão sendo montados bancos de dados específicos que permitem, a partir da informação nominal de inventariados, inventariantes e herdeiros, recompor a riqueza e a transmissão dos bens entre as gerações. Nesse caso, busca-se recuperar a composição da riqueza, visando distinguir bens de raiz, escravos, animais, bens móveis, dívidas ativas e passivas e outros tipos.

\section{Andamento da pesquisa}

Até o momento, foram construídos ou padronizados os seguintes bancos de dados de registros paroquiais:

- São José do Rio das Mortes (Tiradentes): 29.738 registros de batismos (1740 a 1894), 4.285 registros de casamentos (1784 a 1906) e 11.956 registros de óbitos (1733 a 1897); ${ }^{6}$

- São João Del Rei: 50.166 batismos (1735 a 1894), 8.529 casamentos (1729 a 1868) e 12.846 óbitos (1778 a 1822);

- Catas Altas do Mato Dentro: 12.846 batismos (1798 a 1822 e 1862 a 1920) e 1.973 óbitos (1713 a 1730 e 1749 a 1762);

- Belo Horizonte: 5.329 batismos (1862 a 1920) e 1.340 casamentos (1898 a 1922);

- Piranga: 8.045 batismos (1757 a 1887);

- Rio Pomba: 1.124 batismos (1768 a 1796);

- Montes Claros: 1.024 batismos (1872 a 1886).

Em relação à documentação cartorária, estão sendo montados os bancos de dados relativos a:

- São José do Rio das Mortes (Tiradentes), com cerca de 1.200 inventários (1737 a 1850);

- Montes Claros, com cerca de 900 inventários (1804 a 1888);

- Piranga, com cerca de 600 inventários (1713 a 1900).

\footnotetext{
${ }^{5}$ Esses bancos de dados foram montados por membros da equipe desse projeto a partir de projetos de pesquisa financiados pela Fapemig, CNPq, Finep e lpea, dentre outros. É importante destacar que as listas nominativas de habitantes de 1831/32 e de 1838/40 foram digitalizadas pelo Cedeplar/UFMG, e estão disponíveis no site <http://www.poplin.cedeplar. ufmg.br/>, constituindo-se em uma fonte de fácil acesso ao público.

${ }^{6}$ No final de 2011, dois livros de batismo e um de óbitos datados a partir da década de 1870 foram descobertos na Casa Paroquial de Tiradentes e estão sendo digitados desde janeiro de 2012.
} 
Em relação às listas nominativas de habitantes, o projeto incorporará vários conjuntos já digitados em projetos anteriores, a saber:

- 1804: cerca de 40 mil registros;

- 1831-32: cerca de 400 mil registros;

- 1838-40: cerca de 200 mil registros;

- róis de confessados de Mariana, 1802, 1813, 1814, 1820: cerca de 60 mil registros;

- rol de confessados de São José do Rio das Mortes (Tiradentes), 1795: cerca de 12 mil registros.

Com base nos bancos de dados de registros paroquiais, apresentam-se, aqui, alguns resultados preliminares sobre o movimento sazonal dos batismos, casamentos e óbitos ocorridos no período estudado, distribuídos pelos meses, para as paróquias de São José do Rio das Mortes, São João Del Rei, Catas Altas do Mato Dentro, Belo Horizonte e Rio Pomba.

O Gráfico 1 mostra os nascimentos registrados nas paróquias de São João Del Rei, São José do Rio das Mortes, Rio Pomba e Belo Horizonte. Não se observam grandes variações entre os meses, exceto um ligeiro predomínio no segundo semestre. Rio Pomba apresenta variações bruscas que parecem se relacionar com problemas na fonte de dados.

No Gráfico 2, verifica-se que os casamentos nas paróquias de São João Del Rei e de São José do Rio das Mortes concentram-se em fevereiro e novembro, antecedendo os meses de março/abril e dezembro. A repulsa por esses últimos meses associa-se à recomendação da Igreja Católica para que não se realizassem matrimônios nos períodos da Quaresma e do Advento.

O Gráfico 3 apresenta a distribuição dos óbitos nas paróquias de São João Del Rei, São José do Rio das Mortes e Catas Altas do Mato Dentro. De forma semelhante aos nascimentos, não há grandes picos de mortalidade ao longo do ano. A exceção ocorre em Catas Altas, que mostra maiores concentrações em janeiro, abril e julho. Tal excepcionalidade merecerá maiores investigações no decorrer da pesquisa.

Os gráficos apresentados apontam para uma boa qualidade da maioria dos bancos de dados analisados até o momento, os

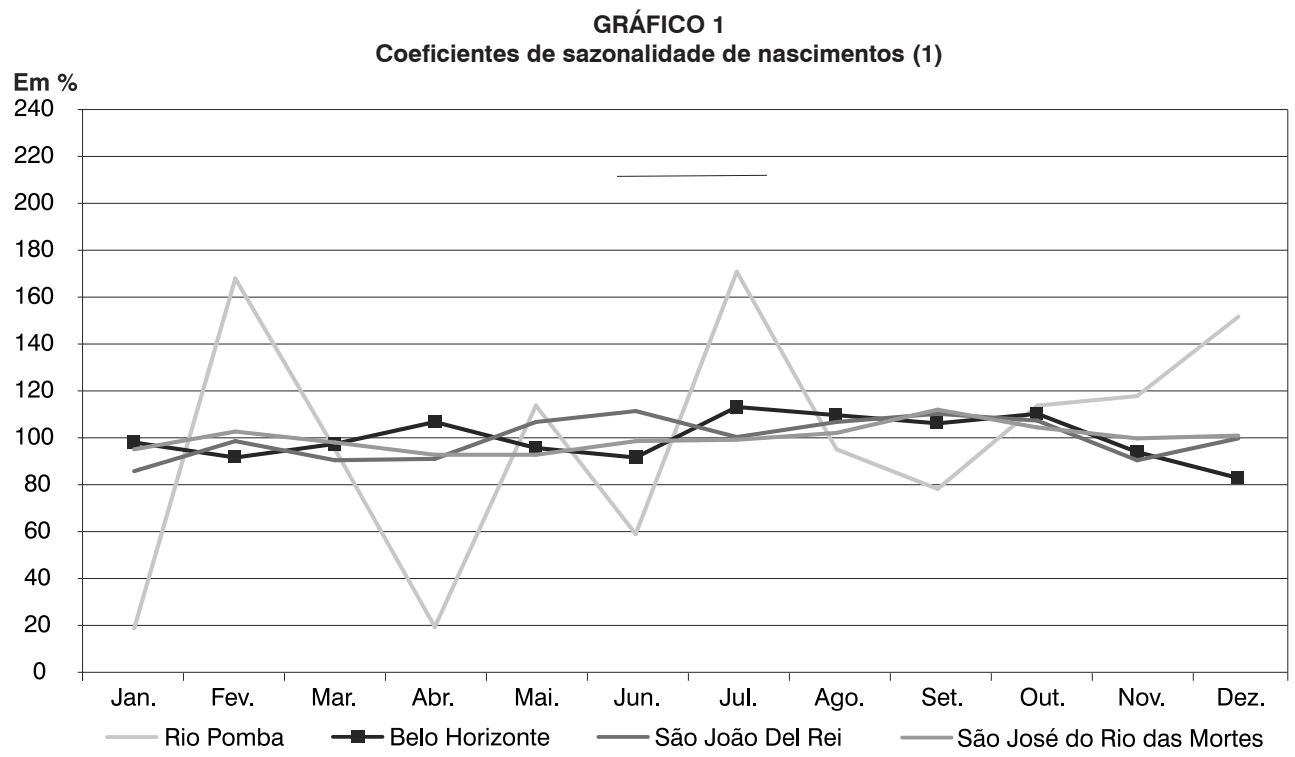

Fonte: Registros Paroquiais de Batismos de São José do Rio das Mortes, São João Del Rei, Rio Pomba e Belo Horizonte.

(1) São José do Rio das Mortes: 1745-1894; São João Del Rei: 1746-1895; Rio Pomba: 1768-1796; Belo Horizonte: 1862-1920. 
GRÁFICO 2

Coeficientes de sazonalidade de casamentos (1)

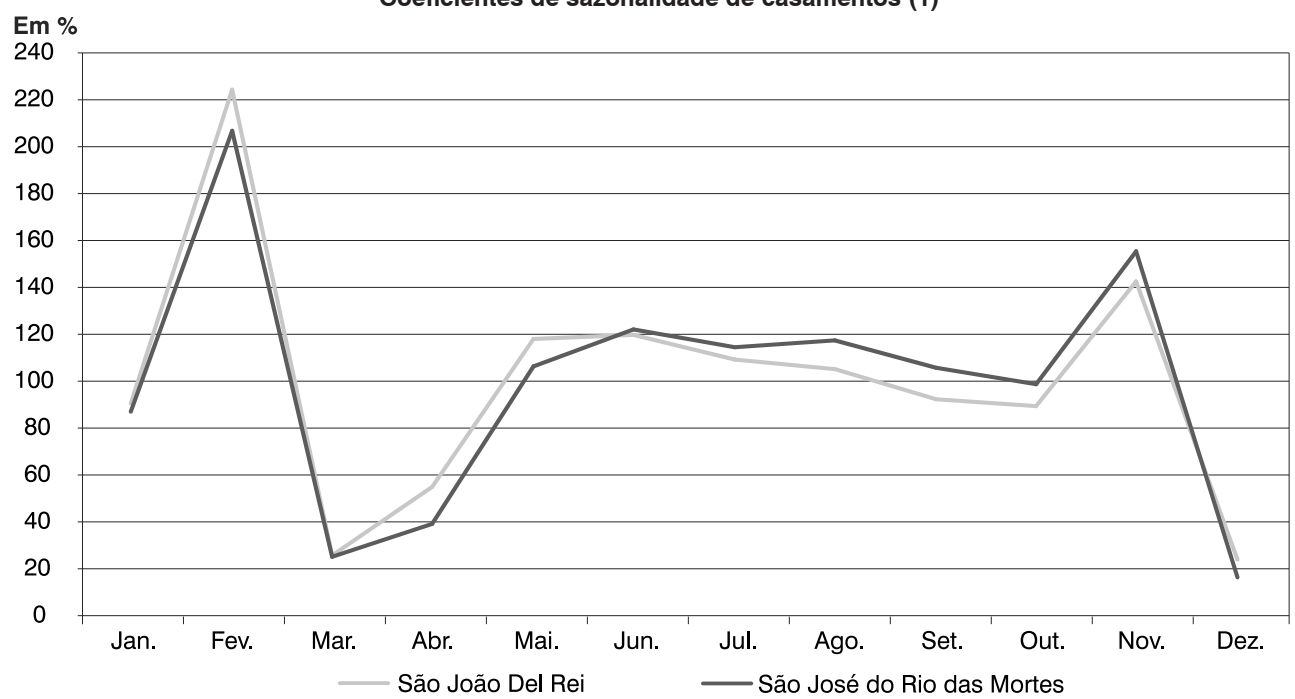

Fonte: Registros Paroquiais de Casamentos de São João Del Rei e São José do Rio das Mortes.

(1) São João Del Rei: 1729-1858; São José do Rio das Mortes: 1784-1906.

\section{GRÁFICO 3}

Coeficientes de sazonalidade de óbitos (1)

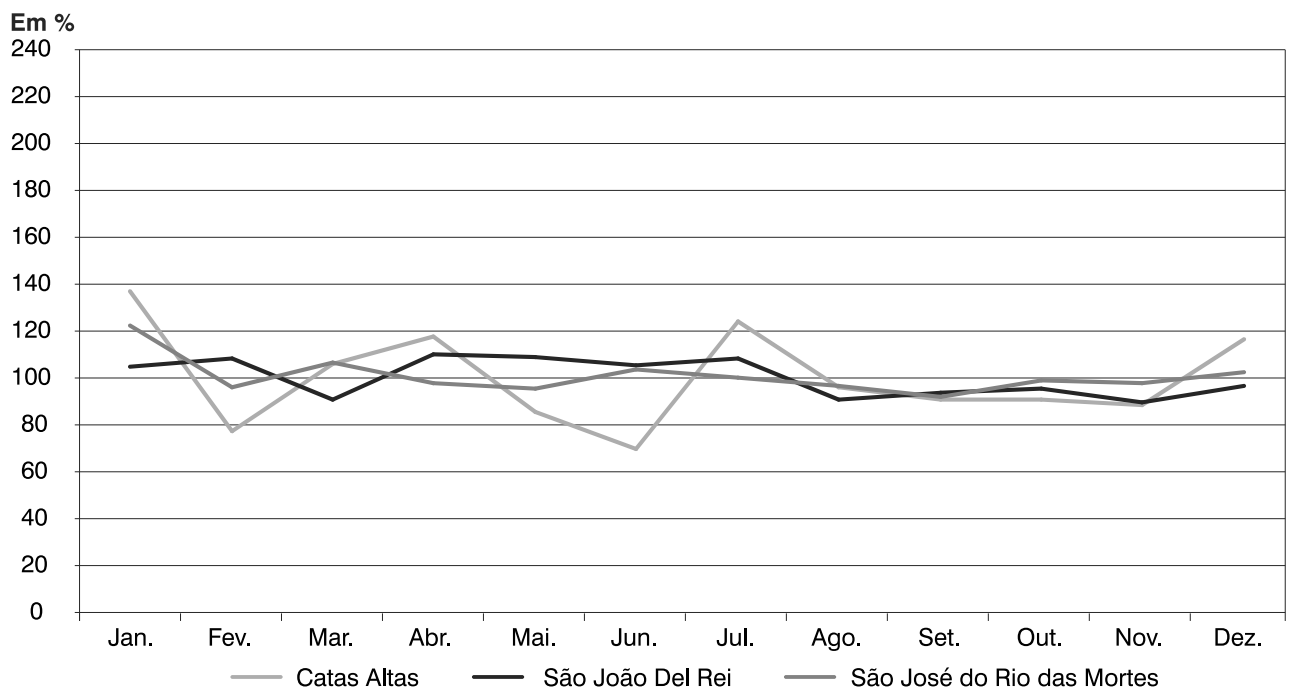

Fonte: Registros Paroquiais de Óbitos de Catas Altas do Mato Dentro, São José do Rio das Mortes e São João Del Rei.

(1) Catas Altas do Mato Dentro: 1716-1723 e 1749-1761; São José do Rio das Mortes: 1753-1868; São João Del Rei: $1782-1822$.

quais apresentaram padrões similares e esperados de distribuição anual, condizentes com outros resultados encontrados na bibliografia. Este é apenas um primeiro passo em direção à verificação da qualidade dos dados, mas serve como base para a continuidade do trabalho de construção de novos bancos de dados. 


\section{Considerações finais}

Com o avanço da pesquisa, pretendese que seus resultados se apresentem de dois modos: estudos monográficos das localidades selecionadas, de modo a se compreender o entrecruzamento desses regimes demográficos em um espaço geográfico específico, considerando-se as variações de atividade econômica e de posição social dos agentes; e estudos comparativos, que incluam o espaço geográfico como variável a ser testada na compreensão dos regimes demográficos observáveis para determinadas atividades econômicas e posições sociais. Ademais, a articulação desses níveis de abordagem permitirá avançar na definição de outros regimes demográficos que não aqueles hipoteticamente apontados aqui.

Os resultados parciais serão sempre comparados com outras pesquisas já realizadas ou em andamento para outras regiões brasileiras e para outros países da América do Sul e da Europa. Destacam-se as possibilidades de comparação com São Paulo, Rio Grande do Sul, Pará, Ceará e Rio de Janeiro. Por outro lado, revela-se muito útil comparar os mesmos resultados com a realidade europeia, sobretudo portuguesa. Em relação a Portugal, são muito discutidas as proximidades entre Minho e Minas quanto a seus sistemas familiares, mas efetivamente pouco se

\section{Referências}

ANDRADE, C. V. de. Domicílios mineiros oitocentistas: uma aplicação do método Grade of Membership (GoM). Dissertação (Mestrado em Demografia). Belo Horizonte: UFMG, 2001.

BOTELHO, T. R. População e nação no Brasil do século XIX. Tese (Doutorado em História Social). São Paulo: USP, 1998.

LIBBY, D. C. Transformação e trabalho em uma economia escravista: Minas Gerais no século XIX. São Paulo: Brasiliense, 1988. fez para avançar no entendimento dessa hipótese de trabalho. Como contraponto, pretende-se verificar como se desenrolaram processos semelhantes em países vizinhos ao Brasil, notadamente Argentina e Uruguai.

Para a construção de indicadores que permitam perceber mudanças e permanências em relação aos regimes demográficos coloniais e visualizar as modificações em face dos processos de transformação política e social que caracterizam o período de 1850 a 1940, pretende-se utilizar o ambiente SIG (Sistema de Informações Geográficas), sobretudo em nível infraprovincial/ infraestadual (termos/municípios). Esse é um recurso ainda pouco empregado pelos historiadores, mas com enorme potencial quando o espaço é uma variável crucial para as análises empreendidas.

Outro aspecto importante da proposta é o uso das ferramentas de trabalho na Internet. Pretende-se disponibilizar bases de dados e imagens digitais na World Wide Web. Para tanto, vamos nos valer da experiência acumulada pelo Laboratório Multimídia de Pesquisa Histórica (LAMPEH), fundado em 2003 numa iniciativa do Departamento de História e da Biblioteca Central da UFV, onde está localizado. Pretende-se que o Núcleo de Excelência utilize essa experiência para disponibilizar on-line, para seus pesquisadores e para a comunidade em geral, os resultados das pesquisas em andamento.

LIBBY, D. C.; HARGREAVES, L. G. F.; MARTINS, M. do C. S. Inventário de acervos documentais históricos do Estado de Minas Gerais: metodologia, resultados e diagnósticos preliminares. Varia Historia, n. 22, p. 183-206, janeiro 1999.

MARCÍLIO, M. L. Sistemas demográficos no Brasil do século XIX. In: MARCíLIO, M. L. (Org.). População \& sociedade: evolução das sociedades pré-industriais. Petrópolis: Vozes, 1984, p. 193-207. 
MARTINS, R. B. A economia escravista de Minas Gerais no século XIX. Belo Horizonte: Cedeplar, 1980.

. Minas Gerais no século XIX: tráfico e apego à escravidão em uma economia não-exportadora. Estudos Econômicos, v. 23, n. 1, 1983.

NADALIN, S. O. A população no passado colonial brasileiro: mobilidade versus estabilidade. Topoi, Rio de Janeiro, v. 4, n. 7, p. 222-275, 2003.

PAIVA, C. A. População e economia nas Minas Gerais do século XIX. Tese
(Doutorado em História Social). São Paulo: USP, 1996.

RODARTE, M. M. S. O trabalho do fogo: perfis de domicílios enquanto unidades de produção e reprodução na Minas Gerais. Tese (Doutorado em Demografia). Belo Horizonte: UFMG, 2008.

SENRA, N. de C. Estatísticas desejadas: 1822-c. 1889. Rio de Janeiro: IBGE, 2006.

SLENES, R. Os múltiplos de porcos e diamantes: a economia escravista de Minas Gerais no século XIX. Cadernos do IFCH/ Unicamp, Campinas, 17, 1985.

Recebido para publicação em 20/01/2012 Aceito para publicação em 02/03/2012 